\title{
KAJIAN SEBARAN LOGAM BERAT TIMBAL (Pb) DAN KROMIUM (Cr) PADA SEDIMEN DI SEKITAR PERAIRAN TELUK LAMPUNG
}

\author{
Fatimah Milasari ${ }^{1}$, Diky Hidayat $^{1 *}$, Rinawati $^{1}$, R. Supriyanto ${ }^{1}$, Agung Abadi Kiswandono ${ }^{1}$ \\ ${ }^{1}$ Jurusan Kimia, FMIPA, Universitas Lampung, Bandar Lampung, 35141 \\ diky.hidayat@fmipa.unila.ac.id
}

\begin{tabular}{|l|}
\hline Artikel Info \\
Diterima \\
tanggal \\
12.09 .2019 \\
Disetujui \\
publikasi \\
tanggal \\
30.042020 \\
Kata kunci : \\
Cr, Pb, \\
Sedimen, \\
Teluk \\
Lampung. \\
\hline
\end{tabular}

\begin{abstract}
ABSTRAK
Telah dilakukan kajian sebaran logam berat Timbal $(\mathrm{Pb})$ dan Kromium $(\mathrm{Cr})$ pada sedimen di sekitar perairan Teluk Lampung. Konsentrasi logam $\mathrm{Pb}$ dan $\mathrm{Cr}$ ditentukan dengan menggunakan spektofotometer serapan atom (SSA) dengan menggunakan tiga validasi metode yaitu limit deteksi, presisi (ketelitian) dan linieritas. Hasil analisil menunjukan konsentrasi logam $\mathrm{Pb}$ pada sedimen di sekitar Perairan Teluk Lampung berada pada rentang 77,6673 $\pm 0,1549$ ppm hingga $80,1263 \pm 0,944 \mathrm{ppm}$.Konsentrasi logam berat Cr pada sampel sedimen di perairan Teluk Lampung berada pada rentang 48,7350 $\pm 0,3638$ ppm sampai 66,0250 \pm $0,1900 \mathrm{ppm}$. Nilai konsentrasi logam berat $\mathrm{Pb}$ dan $\mathrm{Cr}$ yang di peroleh dalam penelitian ini berada diantara baku mutu logam berat pada sedimen yang telah di tetapkan oleh National Sediment Quality Survey (USEPA) yaitu 47,82 - 161,06 ppm untuk logam berat $\mathrm{Pb}$ dan $26-110 \mathrm{ppm}$ untuk logam berat Cr.Validasi metode pada penentuan konsentrasi logam berat $\mathrm{Pb}$ dan $\mathrm{Cr}$ pada sedimen menunjukan nilai koefisien korelasi yaitu 99,9\%; limit deteksi untuk masing-masing logam $\mathrm{Pb}$ dan $\mathrm{Cr}$ adalah 0,0000 dan 0,4016; serta presisi dengan nilai RSD $<5 \%$.
\end{abstract}

\section{ABSTRACT}

A study of the distribution of Lead $(\mathrm{Pb})$ and Chromium $(\mathrm{Cr})$ heavy metals in sediments around the waters of Lampung Bay was conducted. $\mathrm{Pb}$ and $\mathrm{Cr}$ metal concentrations were determined using atomic absorption spectrophotometers (AAS) using three validation methods, namely detection limits, precision (accuracy) and linearity. Analytical results show that the concentration of $\mathrm{Pb}$ metal in sediments around Lampung Bay waters is in the range of $77.6673 \pm 0.1549 \mathrm{ppm}$ to $80.1263 \pm 0.944 \mathrm{ppm}$. The concentration of $\mathrm{Cr}$ heavy metals in sediment samples in Lampung Bay waters is in the range of 48.7350 $\pm 0.3638 \mathrm{ppm}$ to $66.0250 \pm 0.1900 \mathrm{ppm}$. The value of the concentration of heavy metals $\mathrm{Pb}$ and $\mathrm{Cr}$ obtained in this study is between the heavy metal quality standards in sediments that have been set by the National Sediment Quality Survey (USEPA), which is 47.82 - $161.06 \mathrm{ppm}$ for Pb heavy metals and 26$110 \mathrm{ppm}$ for Cr.Validation heavy metal method in determining the concentration of $\mathrm{Pb}$ and $\mathrm{Cr}$ heavy metals in sediments showed a correlation coefficient value of $99.9 \%$; the detection limits for each of the $\mathrm{Pb}$ and $\mathrm{Cr}$ metals are 0.0000 and 0.4016 ; and precision with a RSD value $<5 \%$.

\section{PENDAHULUAN}

Bandar Lampung merupakan kota yang berasal dari penggabungan Tanjung Karang dan Teluk Betung yang memiliki wilayah cukup luas serta menyimpan potensi kelautan yang sangat berpengaruh terhadap Provinsi Lampung. Bandar Lampung memiliki daerah pesisir yang

doi: http://dx.doi.org/10.23960/aec.v5.i1.2020.p92-100

Anal.Environ.Chem. 
menjadi pusat kegiatan perindustrian dan ekonomi di Propinsi Lampung. Sudah kita ketahui logam berat memiliki bahaya yang cukup besar, karena toksisitasnya yang tinggi pada makhluk hidup. Jika konsentrasi logam berat di suatu lingkungan berada di atas baku mutu yang telah ditentukan, maka kehadirannya dapat mengganggu kerja sistem organ dalam tubuh organisme yang memanfaatkan air tersebut (Djuangsih dkk., 1982).

Penyebab utama logam berat menjadi bahan pencemar berbahaya karena logam berat tidak dapat dihancurkan (non degradable) oleh organisme hidup di lingkungan dan terakumulasi ke lingkungan, terutama akan mengendap ke dasar perairanmembentuk senyawa kompleks bersama bahan organik dan anorganik secara adsorbsi dan kombinasi (Djuangsih dkk., 1982). Biota air yang hidup dalam perairan tercemar logam berat, dapat mengakumulasi logam berat tersebut dalam jaringan tubuhnya. Makin tinggi kandungan logam dalam perairan akan semakin tinggi pula kandungan logam berat yang terakumulasi dalam tubuh hewan tersebut (Rai et al.,1981).

$\mathrm{Pb}$ atau disebut timbal adalah logam toksik yang bersifat komulatif, sehingga mekanisme toksisitasnya dibedakan menurut beberapa organ yang dipengaruhinya, seperti padasistem haemopoietik, $\mathrm{Pb}$ dapat menghambat sistem pembentukan hemoglobin sehingga menyebabkan anemia, pada sistem saraf pusat dan tepi, dapat menyebabkan gangguan ensepfalopati dan gejala gangguan sistem saraf perifer sedangkan pada ginjal dapat menyebabkan aminoasiduria, fosfaturia, glukosuria,nefropati, fibrosis dan atrofi glomerular.

Jika logam berat kromium terakumulasi dalam tubuh manusia dapat mengakibatkan kerusakan dalam sistem organ tubuh. Efek toksisitas kromium $(\mathrm{Cr})$ dapat merusak serta mengiritasi hidung, paru-paru, lambung, dan usus. Mengkonsumsi makanan berbahan kromium dalam jumlah yang sangat besar, menyebabkan gangguan perut, bisul, kejang, ginjal, kerusakan hati, dan bahkan kematian (Pallar, 1994).

Berdasarkan uraian di atas, perlu dilakukan kajian sebaran logam berat kromium (Cr) dan timbal $(\mathrm{Pb})$ pada sedimen di wilayah perairan sekitar Teluk Lampung sehingga dapat mencerminkan tingkat pencemaran yang sesungguhnya. Logam berat kromium $(\mathrm{Cr})$ dan timbal $(\mathrm{Pb})$ dianalisis dengan menggunakan Spektrofotometer Serapan Atom (SSA) dimana alat ini dapat digunakan untuk menentukan unsur di dalam suatu bahan dengan kepekaan, ketelitian serta selektifitas yang tinggi.

doi: http://dx.doi.org/10.23960/aec.v5.i1.2020.p92-100 


\section{METODE}

\section{Alat dan Bahan}

Alat: alat gelas standar penelitian, cawan petri, neraca analitik, oven, stirer, desikator, $\mathrm{PbSO}_{4}$, dan instrumen Spektrofotometer Serapan Atom (AAS).

Bahan: $\mathrm{H}_{2} \mathrm{SO}_{4}$ (Merck), $\mathrm{NaOH}$ (Merck), $\mathrm{HCl}$ (Merck), akuades.

\section{Prosedur}

\section{Lokasi Pengambilan Sampel}

Sampel sedimen diambil di bagian pesisir pantai pada 10 titik dengan pengulangan empat kali. Sedimen diambil dengan menggunakan Eckman Grab, kemudian dimasukkan ke dalam wadah plastik yang akan selanjutnya di bawa ke laboratorium untuk dianalisis.

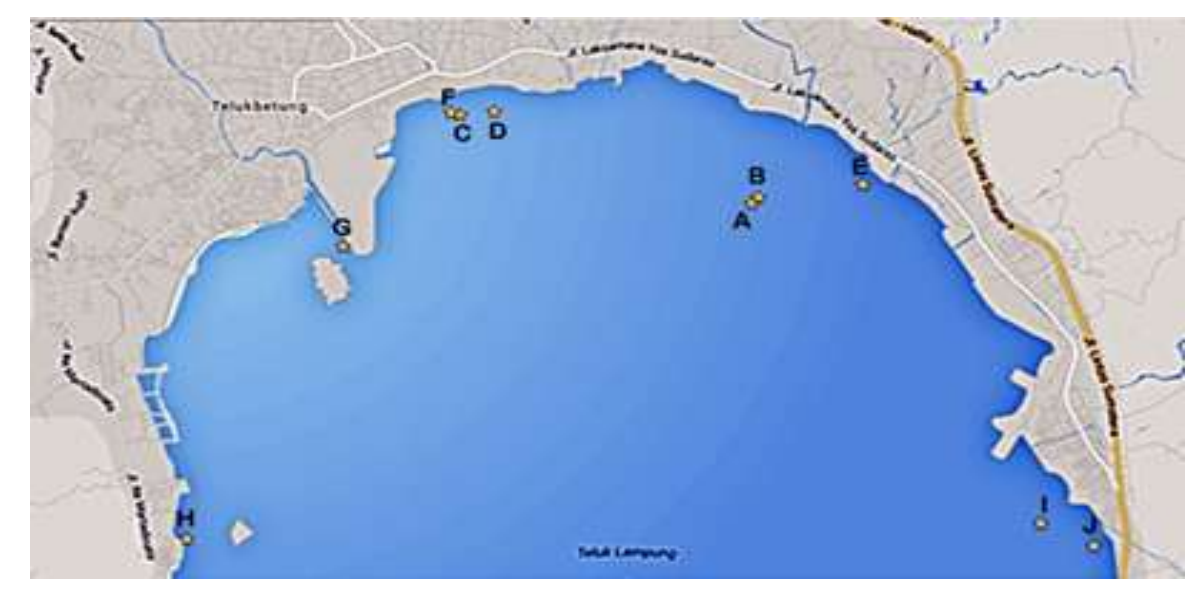

Gambar 1. Lokasi Pengambilan Sampel (Google Map) 
Tabel 1. Lokasi Pengambilan Sampel

\begin{tabular}{|c|c|c|}
\hline $\begin{array}{c}\text { Kode } \\
\text { Sampel }\end{array}$ & Lokasi Pengambilan Sampel & Titik Koordinasi \\
\hline A & Pesisir Muara Sunagi Way Kuala & $\begin{array}{l}0,5^{\circ} 27^{\prime} 24,0^{\prime \prime} \mathrm{LS} \mathrm{S} \\
105^{\circ} 17^{\prime} 52,6^{\prime \prime} \mathrm{LU} \mathrm{E}\end{array}$ \\
\hline B & Muara Sungai Way Kuala & $\begin{array}{c}0,5^{\circ} 27,26,0^{\prime \prime} \text { LS S } \\
105^{\circ} 17,50,5^{\prime \prime} \text { LU E }\end{array}$ \\
\hline $\mathrm{C}$ & Kawasan Pemukiman Penduduk & $\begin{array}{l}0,5^{\circ} 26^{\prime} 58,3 \text { " } \mathrm{LS} \mathrm{S} \\
105^{\circ} 16^{\prime} 29,3^{\prime \prime} \mathrm{LU} \mathrm{E}\end{array}$ \\
\hline $\mathrm{D}$ & Kawasan Pemukiman Penduduk & $\begin{array}{l}0,5^{\circ} 26^{\prime} 57,2^{\prime \prime} \text { LS S } \\
105^{\circ} 16^{\prime} 39,0 \text { " LU E }\end{array}$ \\
\hline $\mathrm{E}$ & Kawasan Way Lunik & $\begin{array}{l}0,5^{\circ} 27^{\prime} 19,9 \text { " LS S } \\
105^{\circ} 18^{\prime} 21,5^{\prime \prime} \text { LU E }\end{array}$ \\
\hline $\mathrm{F}$ & $\begin{array}{l}\text { Kawasan Tempat Pelelangan Ikan Ujung } \\
\text { Bom }\end{array}$ & $\begin{array}{l}0,5^{\circ} 26^{\prime} 58,3 \text { " " LS S } \\
105^{\circ} 16^{\prime} 29,3 \text { " LU E }\end{array}$ \\
\hline G & $\begin{array}{l}\text { Kawasan Pulau Pasaran/Muara Way } \\
\text { Kuripan }\end{array}$ & $\begin{array}{l}0,5^{\circ} 27,37,9 \text { " LS S } \\
105^{\circ} 15,58,6^{\prime \prime ~ L U ~ E ~}\end{array}$ \\
\hline $\mathrm{H}$ & $\begin{array}{l}\text { Kawasan Tempat Pelelangan } \\
\text { Ikan/Lempasing }\end{array}$ & $\begin{array}{l}0,5^{\circ} 29^{\prime} 12,9 \text { ” LS S } \\
105^{\circ} 15^{\prime} 10,4^{\prime \prime} \text { LU E }\end{array}$ \\
\hline I & Kawasan Industri Pertamina & $\begin{array}{l}0,5^{\circ} 29^{\prime} 05,8^{\prime \prime} \text { LS S } \\
105^{\circ} 19^{\prime} 10,9^{\prime} \text { LU E }\end{array}$ \\
\hline $\mathrm{J}$ & Kawasan Pemukiman Penduduk & $\begin{array}{l}0,5^{\circ} 29^{\prime} 12,99^{\prime \prime} \text { LS S } \\
105^{\circ} 19^{\prime} 25,8^{\prime \prime} \text { LU E }\end{array}$ \\
\hline
\end{tabular}

2. Preparasi Sampel untuk Penentuan Kadar Logam $\mathrm{Pb}$

Sedimen basah dikeringkan dengan sinar matahari kemudian dikeringkan kembali dalam oven $100{ }^{\circ} \mathrm{C}$ selama 1 jam selanjutnya sedimen kering digerus. Sedimen yang telah digerus kemudian ditimbang 10 gram dan dimasukkan ke dalam gelas piala dan ditambahkan $20 \mathrm{ml}$ $\mathrm{HNO}_{3}$ dan digoyangkan selama 30 menit, selanjutnya didiamkan selama 3 jam pada suhu ruang. Setelah didiamkan selama 3 jam, ditambahkan $50 \mathrm{~mL}$ akuades kemudian disaring dengan menggunakan kertas saring. Sisa sedimen pada kertas saring dicuci dengan $5 \mathrm{~mL}$ akuades sebanyak lima kali pengulangan sampai $\mathrm{pH} 2-3$. Filtrat yang dihasilkan kemudian diukur dengan Spektrofotometer Serapan Atom untuk menentukan kadar logam $\mathrm{Pb}$.

\section{Preparasi Sampel Untuk Menentukan Kadar Logam Cr}

Sedimen basah dikeringkan dengan sinar matahari kemudian dikeringkan kembali dalam oven $100{ }^{\circ} \mathrm{C}$ selama 1 jam selanjutnya sedimen kering digerus. Sedimen yang telah digerus kemudian ditimbang 10 gram dimasukkan ke dalam gelas piala dan ditambahkancampuran $\mathrm{HCl}$ 
dan $\mathrm{HNO}_{3}$ dengan perbandingan 3 : 1jumlah volume yang dipakai $20 \mathrm{ml}$. Setelah itu campuran larutan digoyangkan selama 30 menit, selanjutnya didiamkan selama 3 jam pada suhu ruang. Setelah didiamkan selama 3 jam, ditambahkan $50 \mathrm{~mL}$ akuades kemudian disaring dengan menggunakan kertas saring. Sisa sedimen pada kertas saring dicuci dengan $5 \mathrm{~mL}$ akuades sebanyak lima kali pengulangan sampai pH 2-3. Filtrat yang dihasilkan kemudian diukur dengan Spektrofotometer Serapan Atom untuk menentukan kadar logam Cr.

\section{HASIL DAN PEMBAHASAN}

Pengambilan sampel dilakukan pada bulan Maret 2015 dengan menggunakan alat Eckmen Grap yang terbuat dari Stainnles Steel. Pada saat pengambilan sampel kondisi iklim di kota Bandar Lampung sedang mengalami musim hujan. Iklim merupakan faktor yang mempengaruhi konsentrasi logam berat dalam suatu badan perairan. Pada musim hujan kadar logam diperairan meningkat, hal ini disebabkan tingginya laju erosi pada permukaan tanah yang terbawa ke dalam badan sungai, sehingga sedimen dalam sungai yang diduga mengandung logam berat akan terbawa oleh arus sungai menuju muara dan pesisir pantai dan pada akhirnya terjadi proses sedimentasi.

Dalam penelitian ini dilakukan pengukuran parameter fisik dan kimia pada air dan sedimen seperti pengukuran $\mathrm{pH}$, temperatur dan kedalaman yang berpengaruh pada proses sedimentasi pada logam berat di perairan Teluk Lampung. Pengukuran parameter fisik dan kimia tersebut dilakukan secara langsung di lapangan.

\section{Pengaruh Parameter Temperatur pada Air Teluk Lampung}

Berdasarkan hasil pengukuran temperatur air Teluk Lampung dapat dilihat bahwa temperatur air Teluk Lampung dari 10 titik kawasan tidak ada perbedaan yaitu berkisaran $25{ }^{\circ} \mathrm{C}$.Kondisi temperatur yang optimum bagi pertumbuhan organisme perairan berkisaran $20-30{ }^{\circ} \mathrm{C}$ (Effendi, 2003). Pada kondisi tersebut maka temperatur perairan di titik kawasan sangat mendukung bagi kehidupan orgnisme di perairan.

Tempertur air laut yang lebih dingin akan meningkatkan adsorpsi logam berat ke partikulat untuk mengendap ke dasar laut. Sementara saat temperatur air laut naik senyawa logam berat akan melarut di air laut karena penurunan laju adsorpsi ke dalam partikulat (Effendi, 2003).

doi: http://dx.doi.org/10.23960/aec.v5.i1.2020.p92-100

Anal.Environ.Chem. 
2. Pengaruh parameter $\mathrm{pH}$ pada air Teluk Lampung

Hasil rata-rata pengukuran $\mathrm{pH}$ air Teluk Lampung di setiap titik berkisar antara 6,538,23 . Hal ini masih berada pada rentang normal namun harus tetap diwaspadai karena setiap hari $\mathrm{pH}$ air laut akan terus berubah dalam rentang yang tidak jauh.Sebagian besar biota perairan sensitif terhadap perubahan $\mathrm{pH}$ dan bertahan dalam kondisi $\mathrm{pH}$ sekitar 7-8,5 (Effendi,2003).

Pada $\mathrm{pH}$ yang rendah hampir semua logam akan cenderung larut dalam air dan berpindah tempat sesuai dengan kondisi air laut. Sedangkan pada pH tinggi maka logam akan cenderung mengalami pengendapan ke dalam sedimen. Kenaikan $\mathrm{pH}$ akan menurunkan kelarutan logam dalam air, karena kenaikan $\mathrm{pH}$ akan mengubah kestabilan dari bentuk karbonat menjadi hidroksida yang membentuk ikatan dengan partikel pada suatu badan air sehingga membentuk lumpur (Pallar, 1994).

Menurut Cholik (2005) tinggi rendahnya $\mathrm{pH}$ dipengaruhi fluktuasi kandungan $\mathrm{CO}_{2}$ terlarut dan memiliki pola hubungan terbalik. Semakin tinggi $\mathrm{CO}_{2}$ perairan maka $\mathrm{pH}$ akan menurun demikian pula sebaliknya.

\section{Pengaruh Parameter Kedalaman pada Air Teluk Lampung}

Kedalaman saat pengambilan sampel berkisar antara 1-27 meter. Kedalaman suatu perairan berhubungan erat dengan produktivitas, suhu, penetrasi cahaya, densitas, kandungan oksigen serta unsur hara (Hutabarat dan Evans, 2006). Kedalaman merupakan salah satu parameter yang penting dalam memecahkan masalah teknik berbagai pesisir serta erosi.

\section{Sebaran Logam Berat Cr pada Sedimen di Teluk Lampung}

Konsentrasi logam berat kromium tertinggi ditunjukan pada titik B (kawasan muara Way Kuala) sebesar 66,0250 \pm 0,1900ppm dan konsentrasi logam berat kromium terendah berada pada titik $\mathbf{J}$ (kawasan pemukiman penduduk) sebesar 48,7350 \pm 0,3638 ppm. Menurut US EPA (2004), baku mutu logam Cr dalam sedimen berkisar 26- 110 ppm. 
Tabel 2. Konsentrasi Logam Cr pada Sedimen

\begin{tabular}{cccc}
\hline $\begin{array}{c}\text { Titik Pengambilan } \\
\text { Sampel }\end{array}$ & $\overline{\mathbf{M}}(\mathrm{ppm})$ & $\mathrm{SD}(\mathrm{ppm})$ & $\overline{\mathbf{M}} \pm \mathrm{SD}(\mathrm{ppm})$ \\
\hline A & 65,6450 & 0,3638 & $65,6450 \pm 0,3638$ \\
B & 66,0250 & 0,1900 & $66,0250 \pm 0,1900$ \\
C & 52,3450 & 1,7379 & $52,3450 \pm 1,7379$ \\
D & 52,5350 & 1,4345 & $52,5350 \pm 1,4345$ \\
E & 53,9600 & 0,3103 & $53,9600 \pm 0,3103$ \\
F & 56,0500 & 0,2194 & $56,0500 \pm 0,2194$ \\
G & 59,0900 & 0,9046 & $59,0900 \pm 0,9046$ \\
H & 50,9200 & 0,4388 & $50,9200 \pm 0,4388$ \\
I & 50,2550 & 0,6490 & $50,2550 \pm 0,6490$ \\
J & 48,7350 & 0,3638 & $48,7350 \pm 0,3638$ \\
\hline
\end{tabular}

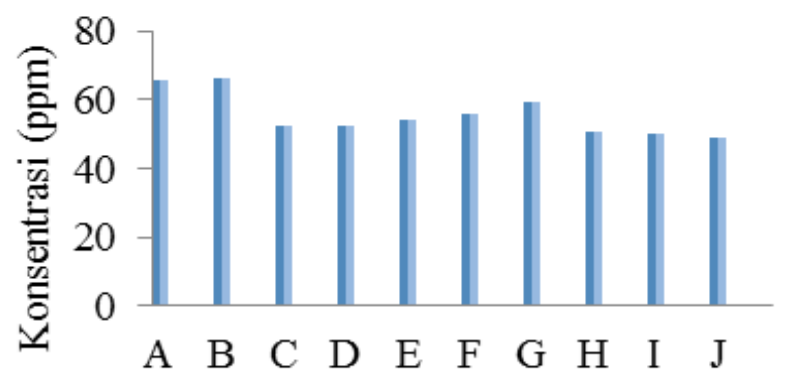

Titik Pengambilan

Gambar 2. Konsentrasi Logam Berat $\mathrm{Cr}$

5. Sebaran Logam Berat Timbal (Pb) pada Sedimen di Teluk Lampung

Tabel 3.Konsentrasi Logam $\mathrm{Pb}$ pada Sedimen

\begin{tabular}{cccc}
\hline $\begin{array}{c}\text { Titik Pengambilan } \\
\text { Sampel }\end{array}$ & $(\mathrm{ppm})$ & $\mathrm{SD}(\mathrm{ppm})$ & $\pm \mathrm{SD}(\mathrm{ppm})$ \\
\hline A & 80,1263 & 0,9445 & $80,1263 \pm 0,9445$ \\
B & 79,6165 & 0,7088 & $79,6165 \pm 0,7088$ \\
C & 79,9164 & 0,1509 & $79,9164 \pm 0,1509$ \\
D & 78,7169 & 0,3963 & $78,7169 \pm 0,3963$ \\
E & 77,6673 & 0,1549 & $77,6673 \pm 0,1549$ \\
F & 78,9268 & 0,0979 & $78,9268 \pm 0,0979$ \\
G & 79,4366 & 0,2999 & $79,4366 \pm 0,2999$ \\
H & 78,9268 & 0,1696 & $78,9268 \pm 0,1696$ \\
I & 78,7169 & 0,2271 & $78,7169 \pm 0,2271$ \\
J & 79,0467 & 0,2591 & $79,0467 \pm 0,2591$ \\
\hline
\end{tabular}

doi: http://dx.doi.org/10.23960/aec.v5.i1.2020.p92-100 


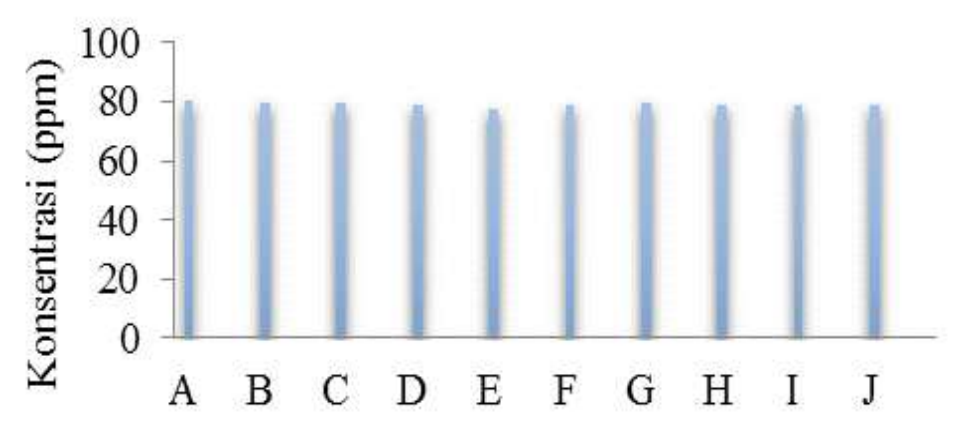

Titik Pengambilan

\section{Gambar 3. Konsentrasi Logam $\mathrm{Pb}$}

Konsentrasi logam berat timbal yang tertinggi pada kawasan pesisir Way Kuala dengan sebesar $80,1263 \pm 0,9445 \mathrm{ppm}$ dan konsentrasi terendah pada kawasan Way Lunik sebesar 77,6673 \pm 0,1549 ppm. Menurut USEPA (2004), baku mutu logam Pb dalam sedimen berkisar 47,82 $161,06 \mathrm{ppm}$.

\section{KESIMPULAN}

Berdasarkan hasil analisis dan penelitian pada penelitian ini, maka dapat diambil kesimpulan sebagai berikut:

1. Konsentrasi logam Timbal ( $\mathrm{Pb}$ ) pada sedimen di Perairan Teluk Lampung berkisar 77,6780,13 ppm. Hal ini sudah menunjukan bahwa perairan Teluk Lampung sudah masuk pada batas bawah indeks pencemaran USEPA logam berat $\mathrm{Pb}$ pada perairan, yaitu pada rentang 47,82-161,06 ppm.

2. Konsentrasi logam Kromium (Cr) pada sedimen di Perairan Teluk Lampung berkisar 44,7350 $-66,0250 \mathrm{ppm}$. Hal ini menunjukan bahwa perairan Teluk Lampung sudah masuk pada batas bawah indeks pencemaran USEPA logam berat Cr pada perairan, yaitu pada rentang $26-110$ ppm.

3. Konsentrasi logam berat timbal $(\mathrm{Pb})$ dan kromium $(\mathrm{Cr})$ tertinggi berada pada titik A dan titik B yaitu di kawasan pesisi dan muara Way Kuala. Hal ini disebabkan karena Sungai Way Kuala merupakan sungai yang mengaliri kota Bandar Lampung dan menjadi pusat pembuangan limbah domestik warga kota Bandar Lampung 


\section{DAFTAR PUSTAKA}

Cholik, F. 2005. Akukultur. Masyarakat Perikanan Nusantara. Taman Akuarium Air Tawar. Jakarta.

Darelanko, M, 2002, HandbookofToxicology, $2^{\text {nd }}$ Edition CRCPress, New York.

Djuangsih, N., A.K. Benito, H. Salim, 1982. Aspek Toksikologi Lingkungan, Laporan Analisis Dampak Lingkungan, Lembaga Ekologi Universitas Padjadjaran, Bandung

Effendi, H. 2003.Telaah Kualitas Air bagi Pengolahan Sumber Daya dan Lingkungan Perairan.Penerbit Kanisius. Yogyakarta.

Hutabarat, Sahala dan Stewart M. Evans. 2006. Pengantar Oseanografi.

Universitas Indonesia. Jakarta

Pallar, H., 1994.Pencemaran dan Toksikologi Logam Berat. Rineka Cipta. Jakarta.

Rai, L.L., J. Gaur and H.D. Kumar. 1981. Phycology and Heavy Metal Pollution. In Biological Review of The Phycology Society. Cambridge University Press London

USEPA (National Sediment Quality Survey). 2004. The Incidence and Severity of Sediment Contamination in Surface Waters of United States, National Sediment Quality Survey $: 2^{\text {nd }}$ Edition. EPA-823-R-04-2007.U. S. Enviromental Protection Agency, Washington D.C.

doi: http://dx.doi.org/10.23960/aec.v5.i1.2020.p92-100

Anal.Environ.Chem. 